\title{
Ten-eleven translocation 1 dysfunction reduces 5-hydroxymethylcytosine expression levels in gastric cancer cells
}

\author{
KUO-CHIANG WANG ${ }^{1}$, CHI-HSIANG KANG ${ }^{1}$, CHUNG-YU TSAI ${ }^{1}$, \\ NAN-HUA CHOU ${ }^{1}$, YA-TING TU ${ }^{2}$, GUAN-CHENG LI ${ }^{2}$, HING-CHUNG LAM ${ }^{3}$, \\ SHIUH-INN LIU ${ }^{1}$, PO-MIN CHANG ${ }^{1}$, YAN-HWAI LIN ${ }^{4}$ and KUO-WANG TSAI ${ }^{2,5,6}$ \\ ${ }^{1}$ Division of General Surgery, Department of Surgery; ${ }^{2}$ Department of Medical Education and Research; ${ }^{3}$ Center for \\ Geriatrics and Gerontology, Kaohsiung Veterans General Hospital; ${ }^{4}$ Laboratory Medicine Division, Zuoying Branch of \\ Kaohsiung Armed Forces General Hospital; ${ }^{5}$ Institute of Biomedical Sciences, National Sun Yat-Sen University, \\ Kaohsiung 813; ${ }^{6}$ Department of Chemical Biology, National Pingtung University of Education, Pingtung 900, Taiwan, R.O.C.
}

Received June 15, 2016; Accepted August 3, 2017

DOI: $10.3892 / \mathrm{ol} .2017 .7264$

\begin{abstract}
A sixth base, 5-hydroxymethylcytosine (5hmC), is formed by the oxidation of 5-methylcytosine $(5 \mathrm{mC})$ via the catalysis of the ten-eleven translocation (TET) protein family in cells. Expression levels of $5 \mathrm{hmC}$ are frequently depleted during carcinogenesis. However, the detailed mechanisms underlying the depletion of $5 \mathrm{hmC}$ expression in gastric cancer cells remains unclear, and further research is required. The present study examined the expression levels of $5 \mathrm{mC}$ and $5 \mathrm{hmC}$ and the expression levels of TET1 and TET2 in gastric cancer tissues using immunohistochemistry. The results revealed that $5 \mathrm{hmC}$ expression levels were markedly lower in gastric cancer tissues compared with corresponding adjacent normal tissues. Furthermore, a decrease in $5 \mathrm{hmC}$ expression levels was associated with a decrease in TET1 protein expression levels in gastric cancer tissues. The ectopic expression level of TET1 may increase the $5 \mathrm{hmC}$ expression level in gastric cancer cells. In addition, the results revealed that TET1 protein expression was markedly different in regards to subcellular localization, and mislocalization was significantly associated with the depletion of $5 \mathrm{hmC}$ expression levels in gastric cancer. Together, the results of the present study indicated that TET1 dysfunction reduces $5 \mathrm{hmC}$ expression levels, and this phenomenon may serve a crucial role in gastric cancer progression.
\end{abstract}

Correspondence to: Dr Kuo-Wang Tsai, Department of Medical Education and Research, Kaohsiung Veterans General Hospital, 386 Ta-Chung 1st Road, Kaohsiung 813, Taiwan, R.O.C.

E-mail: kwtsai@vghks.gov.tw

Dr Yan-Hwai Lin, Laboratory Medicine Division, Zuoying Branch of Kaohsiung Armed Forces General Hospital, 553 Army Road, Kaohsiung 813, Taiwan, R.O.C.

E-mail: breanda.9-9@yahoo.com.tw

Key words: DNA methylation, hydroxylmethylation, gastric cancer, demethylation

\section{Introduction}

Epigenetic regulation includes histone modification and DNA methylation, which are involved in the regulation of cell growth and development in mammals $(1,2)$. The methylation of cytosine occurs via DNA methyltransferases (DNMTs), which use S-adenosylmethionine as the donor for the methyl group. In mammalian cells, DNMT genes are classified into de novo (DNMT3A and DNMT3B) and maintenance (DNMT1) methyltransferases; these genes serve various functions in setting the methylation maps of the mammalian genome (3). During carcinogenesis, the DNA methylation level gradually decreases in the DNA repetitive region, leading to genomic DNA instability (4-7). In general, high methylation of a gene promoter is associated with gene silencing. Numerous tumor suppressors have been identified with a hypermethylated promoter that suppresses their transcription potential in multiple types of human cancer (8-11). Therefore, establishing and maintaining DNA methylation status is essential in human types of cancer.

Previous studies have reported that a sixth base, 5 -hydroxymethylcytosine $(5 \mathrm{hmC})$, is present in a number of tissues, including the muscle, lung, kidney and heart, and is highly expressed inthe brain andembryonic cells (2,12-15).Furthermore, $5 \mathrm{hmC}$ is generated by the oxidation of 5-methylcytosine $(5 \mathrm{mC})$ by ten-eleven translocation protein (TET), and $5 \mathrm{hmC}$ serves critical roles in various tissues $(2,13,15-22)$. Furthermore, $5 \mathrm{hmC}$ has been suggested to serve a crucial role in gene regulation via the demethylation process $(2,13,15-22)$. The two following theories suggest the involvement of $5 \mathrm{hmC}$ in the DNA demethylation process: i) Passive DNA demethylation, where DNMT protein does not recognize the $5 \mathrm{hmC}$-rich region, thus preventing maintenance methylation during DNA replication; ii) active DNA demethylation, where the $5 \mathrm{hmC}$-rich region is recognized by DNA glycosylase protein, which converts $5 \mathrm{hmC}$ to cytosine $(2,13,15-22)$. Previous studies have reported that hyperhydroxymethylation of the promoter region of metalloproteinase and homeobox A9 genes increases the expression levels of these genes $(3,23)$. Therefore, high $5 \mathrm{hmC}$ expression levels in the promoter region may activate gene transcription via the promotion of DNA demethylation $(2,24)$. 
Although $5 \mathrm{mC}$ is the upstream substrate for generating $5 \mathrm{hmC}$ via the catalysis of TET proteins, the expression level and distribution of $5 \mathrm{hmC}$ is not associated with that of $5 \mathrm{mC}$ in human types of cancer (25). Therefore, global DNA hypomethylation in human types of cancer only partially explain the low $5 \mathrm{hmC}$ expression levels in human tumors. Multiple previous studies have indicated that the dysfunction of isocitrate dehydrogenase $[\mathrm{NAPD}(+)) 1 / 2$, activation-induced deaminase and TET genes are associated with aberrant expression of $5 \mathrm{hmC}$ in human cancer cells (16,26-28). However, the mechanism underlying the depletion of $5 \mathrm{hmC}$ expression levels in gastric cancer cells remains unclear. The present study investigated the status of DNA modification and TET1 and TET2 protein expression levels in gastric cancer tissue, and provided another potential explanation for $5 \mathrm{hmC}$ expression level depletion in gastric cancer.

\section{Materials and methods}

Clinical samples and DNA/RNA extraction. A total of 16 gastric cancer and corresponding adjacent normal tissue samples were collected from patients with gastric cancer who underwent surgery at the Department of Surgery, Kaohsiung Veterans General Hospital (Kaohsiung, Taiwan) between July 2013 and August 2014. They did not receive any treatment prior to surgery. These patients included 10 males and 6 females, whose age ranged between 55 and 70 years old. The study protocol was independently reviewed and approved by the Institutional Review Board of Kaohsiung Veterans General Hospital (approval no. VGHKS12-CT3-10). The methods performed were in accordance with approved guidelines, and written informed consent was obtained from all patients prior to enrolment in the present study.

Immunohistochemical (IHC) analysis and scoring. Human gastric carcinoma tissue microarrays, including adjacent normal tissues (cat. no. IMH-341) and tumors (cat. no. IMH-316) from 59 patients with gastric cancer were obtained from Imgenex; Novus Biologicals, LLC (Littleton, CO, USA). IHC analyses were performed using the Novolink Max Polymer Detection System (Leica Microsystems, Ltd., Milton Keynes, UK). The tissue slides were sectioned at a thickness of $5 \mu \mathrm{m}$, deparaffinized in xylene and rehydrated in 100,95 and 75\% ethanol for 3 min each. Antigen retrieval was performed by immersing the slides in Tris-EDTA (10 mM; pH 9.0) for $10 \mathrm{~min}$ at $125^{\circ} \mathrm{C}$ in a pressure boiler. Endogenous peroxidase activity was blocked by incubating the slides for 30 min with $3 \%$ hydrogen peroxide in methanol. The slides were then blocked with protein block buffer $(0.4 \%$ casein in PBS, with stabilizers, surfactant and $0.2 \%$ bronidox $\mathrm{L}$ as a preservative). Following blocking at room temperature (RT) for $30 \mathrm{~min}$, primary antibodies were immediately applied and the slides were incubated overnight at $4^{\circ} \mathrm{C}$ in a wet chamber. The primary antibodies used were mouse monoclonal anti-5mC (1:500; cat. no. ab10805; Abcam, Cambridge, UK); rabbit polyclonal anti-5hmC (1:1,000; cat. no. 39769; Active Motif, Carlsbad, CA, USA), rabbit polyclonal anti-TET1 (1:150; cat. no. TA309902; OriGene Technologies, Inc., Rockville, MD, USA) and goat polyclonal anti-TET2 (1:50; cat. no. OAEB00839; AVIVA Systems Biology, San Diego, CA, USA) in primary antibody diluent
(ScyTek Laboratories, Logan, UT, USA). Following washing with PBS, the slides were incubated with a rabbit anti-mouse poly-horseradish peroxidase (HRP)-immunoglobulin (Ig)G (cat. no. RE7159; Leica Microsystems, Ltd., Milton Keynes, UK) and goat anti-rabbit poly-HRP-IgG (cat. no. RE7161; Leica Microsystems, Ltd., Milton Keynes, UK) for $10 \mathrm{~min}$ at RT. Finally, the color was developed using a $0.03 \%$ diaminobenzidine solution (ScyTek Laboratories) for $2 \mathrm{~min}$ at room temperature. Subsequently the tissue sections were counterstained with hematoxylin for $10 \mathrm{~min}$ at room temperature.

The expression scores of individual candidates for nuclear or cytoplasmic staining were determined on the basis of staining intensity ( 0 , no signal; 1 , mild; 2 , moderate; 3 , strong). The proportion of positively stained tumor cells (scored as $0-100 \%$ ) was evaluated in the whole field of each core. The score of individual candidates was calculated using the following formula: Intensity x percentage of positively stained cells.

Gene expression data. The microarray data of TET1 and TET2 in 311 gastric cancer tissues and 57 adjacent normal tissues were obtained from the Gene Expression Across Normal and Tumor Tissue (GENT) database (http://medicalgenome.kribb.re.kr/GENT/search/search.php) (29).

Western blot analysis. The tissue samples were lysed using a lysis buffer $(50 \mathrm{mM}$ Tris- $\mathrm{HCl}$ at $\mathrm{pH} 8.0,150 \mathrm{mM} \mathrm{NaCl}$, $1 \% \mathrm{NP}-40,0.02 \%$ sodium azide, $1 \mu \mathrm{g} / \mathrm{ml}$ aproteinin and $1 \mathrm{mM}$ PMSF) at $4^{\circ} \mathrm{C}$ for $30 \mathrm{~min}$. The lysates were collected and centrifuged at $16,000 \mathrm{x} \mathrm{g}$ at $4^{\circ} \mathrm{C}$ for $10 \mathrm{~min}$ to remove cell debris. Protein assays were performed using the Bio-Rad Protein Assay kit (Bio-Rad Laboratories, Inc., Hercules, CA, USA) based on the Bradford dye-binding procedure (30). Protein samples $(60 \mu \mathrm{g})$ were separated by $8-10 \%$ SDS-PAGE. The separated proteins were then electrotransferred onto nitrocellulose membranes (GE Healthcare, Chicago, IL, USA). Following blocking overnight at $4^{\circ} \mathrm{C}$ using $0.1 \%$ of Tween in PBS supplemented with 5\% skimmed milk, the membranes were incubated with mouse monoclonal anti-TET1 (1:500; cat. no. GTX627420; GeneTex Inc., Irvine, CA, USA), mouse monoclonal anti-green fluorescent protein (GFP; 1:2,000; cat. no. sc-9996; Santa Cruz Biotechnology, Inc., Dallas, TX, USA) and mouse monoclonal anti-actin (1:3,000; cat. no. MAB1501; EMD Millipore, Billerica, MA, USA) for $1 \mathrm{~h}$ in PBS-Tween supplemented with $5 \%$ skimmed milk at room temperature. The membranes were then incubated with HRP-conjugated goat-anti-rabbit-IgG (1:5,000; cat. no. sc-2004; Santa Cruz Biotechnology, Inc., Dallas, TX, USA) or goat-anti-mouse IgG secondary antibodies (1:5,000; cat. no. sc-2005; Santa Cruz Biotechnology, Inc., Dallas, TX, USA) for $1 \mathrm{~h}$ at RT. Following washing three times with PBS-Tween, immunoreactive bands were detected using an enhanced chemiluminescence kit (cat. no. K-12045-D50; Advansta, Inc., Menlo Park, CA, USA).

Gastric cancer cell lines and transfection assay. Human gastric cancer AGS cells were obtained from American Type Culture Collection (Manassas, VA, USA), and cultured in Dulbecco's modified Eagle's medium (Biological Industries Israel Beit-Haemek Ltd., Kibbutz Beit-Haemek, Israel) supplemented with $10 \%$ fetal bovine serum (GE Healthcare 
Life Sciences, Logan, UT, USA) and 1\% penicillin/streptomycin (Sigma-Aldrich; Merck KGaA). In the present study, transfection assay was performed using Lipofectamine ${ }^{\circledR} 2000$ (Invitrogen; Thermo Fisher Scientific, Inc.) according to the manufacturer's protocol.

DNA dot-blot assay. DNA samples were added to the denaturation buffer (0.4 $\mathrm{mM} \mathrm{NaOH}$ and $10 \mathrm{mM}$ EDTA) and denatured at $100^{\circ} \mathrm{C}$ for $10 \mathrm{~min}$. Furthermore, the samples were chilled on ice for $5 \mathrm{~min}$ and applied on a positive-charged nylon membrane (Roche, Basel, Switzerland). The membrane was UV cross-linked and dried for $1 \mathrm{~h}$ at $70^{\circ} \mathrm{C}$. The membranes were probed with rabbit polyclonal anti-5hmC (1:5,000; cat. no. 39769; Active Motif, Carlsbad, CA, USA) at $4^{\circ} \mathrm{C}$ overnight. The membranes were then incubated with HRP-conjugated goat anti-rabbit IgG (1:5,000; cat. no. sc-2004; Santa Cruz Biotechnology, Inc.) for $1 \mathrm{~h}$ at RT. The target bands were visualized using WesternBright enhanced chemiluminescence reagent (Advansta, Inc., Menlo Park, CA, USA) and the results of the immunoreactions were analyzed with a BioSpectrum ${ }^{\circledR} 500$ Imaging System (Ultra-Violet Products Ltd., Cambridge, UK). The membranes were stained with methylene blue (Sigma-Aldrich; Merck KGaA) as a loading control.

Predict nuclear export signals (NESs) by bioinformatic approach. A useful web server (NetNES 1.1) for predicting potential leucine-rich NESs within protein sequences is available at http://www.cbs.dtu.dk/services/NetNES/ (31). The TET1 protein sequences (NP_085128.2) were downloaded from The National Center for Biotechnology Information databases (NCBI; https://www.ncbi.nlm.nih.gov/). TET1 protein sequences in FASTA format was uploaded to NetNES 1.1 website. According to the characteristics and the homology of the NESs (Nuclear export signals), NetNES 1.1 could predict putative NESs within TET1 protein.

In vitro DNA demethylation assay. pEGFP plasmids (Clontech, Mountain View, CA, USA) were completely methylated in vitro using M.SssI methylase enzymes (Invitrogen; Thermo Fisher Scientific, Inc., Waltham, MA, USA). Subsequently, methylated reporter vectors were co-transfected with TET1-FL or TET1-delNLS into AGS gastric cancer cells. Following transfection for 24-48 h, demethylation activity in cells was examined by western blotting as aforementioned.

Statistical analysis. The expression levels of $5 \mathrm{mC}$ and $5 \mathrm{hmC}$ in paired gastric cancer were analyzed using a paired Student's $\mathrm{t}$-test. The expression levels of TET1 and TET2 from the TCGA database and the association between various localizations of TET1 protein and $5 \mathrm{hmC}$ expression levels in human gastric cancer was analyzed using Student's t-tests. The TET1 activity assays were performed in triplicate. The intensity of GFP was quantified using ImageJ Software 1.45s (National Institutes of Health, Bethesda, MD, USA) and presented graphically. The data are presented as the mean \pm standard deviation. $\mathrm{P}<0.05$ was considered to indicate a statistically significant difference and $\mathrm{P}<0.01$ was considered to indicate a highly significant difference.

\section{Results}

$5 \mathrm{hmC}$ expression level depletion in gastric cancer cells. The IHC staining revealed that compared with the corresponding adjacent normal tissues, the expression level of $5 \mathrm{mC}$ was slightly increased and that of $5 \mathrm{hmC}$ was significantly depleted in gastric cancer tissues $(5 \mathrm{mC}, \mathrm{P}=0.03$ and $5 \mathrm{hmC}, \mathrm{P}<0.001$; Fig. $1 \mathrm{~A}$ and $\mathrm{B}$ ). These results indicated that $5 \mathrm{hmC}$ expression level depletion was not due to low $5 \mathrm{mC}$ expression levels in gastric cancer tissues. The potential mechanism underlying $5 \mathrm{hmC}$ expression level depletion may therefore be the dysfunction of metabolic enzymes involved in the DNA demethylation signaling pathway.

Expression levels of TET1/2 in gastric cancer cells. The present study investigated the expression levels of TET1 and TET2 in a gastric cancer tissue array ( $\mathrm{n}=59$ cases) using IHC. TET1 protein expression was markedly decreased and TET2 protein expression was slightly increased in the gastric cancer tissues compared with the adjacent normal tissues (TET1, $\mathrm{P}=0.0002$ and TET2, $\mathrm{P}=0.06$; Fig. $1 \mathrm{C}$ and $\mathrm{D}$ ). This result was further confirmed by mRNA and protein expression level analysis using the GENT database and western blotting, respectively. By analyzing the GENT database, the present study revealed that the transcriptional expression levels of TET1 were substantially decreased in the gastric cancer tissues compared with normal adjacent tissues $(\mathrm{P}<0.001$; Fig. 2A). This result was consistent with that of IHC analyses. Furthermore, as presented in Fig. 2B, compared with the corresponding adjacent normal tissues, the protein expression levels of TET1 were frequently decreased in the tumor tissues (in 8 out of 16 cases). The transfection of TET1 into AGS cells for $24 \mathrm{~h}$ resulted in an increase in 5hmC expression levels (Fig. 2C). These results indicated that the decrease in $5 \mathrm{hmC}$ expression levels in gastric cancer may be induced by low TET1 protein expression levels.

Nuclear exclusion of TET1 is associated with $5 \mathrm{hmC}$ expression level depletion in gastric cancer. The present study not only observed the depletion of TET1 protein expression levels in gastric cancer tissues, but also observed marked differences in its subcellular localization. As presented in Fig. 3A, TET1 protein was detected in three subcellular localizations in the gastric cancer tissues: Cytoplasm (left panel); cytoplasm and nucleus (middle panel); nuclear accumulation (right panel). Furthermore, the present study detected TET1 expression level in gastric cancer tissue samples, except in 3 samples where no TET1 protein expression was observed. Of the 59 tumor samples, the protein expression level was restricted to the cytoplasm without nuclear staining in $36(61 \%)$ samples, in the cytoplasm and nucleus in $9(15.3 \%)$ samples and predominantly in the nucleus in $11(18.6 \%)$ samples. Furthermore, as presented in Fig. 3B, TET1 nuclear localization was associated with $5 \mathrm{hmC}$ expression levels. The comparison of the $5 \mathrm{hmC}$ expression levels with TET1 cellular localization revealed that TET1 nuclear staining had a significant association with high $5 \mathrm{hmC}$ expression levels $(\mathrm{P}=0.001)$ in gastric cancer (Fig. $3 \mathrm{C}$ ). These results implied that TET1 protein may shuttle between the nucleus and the cytoplasm. Using bioinformatics, the present study identified three nuclear localization signals (NLS; 

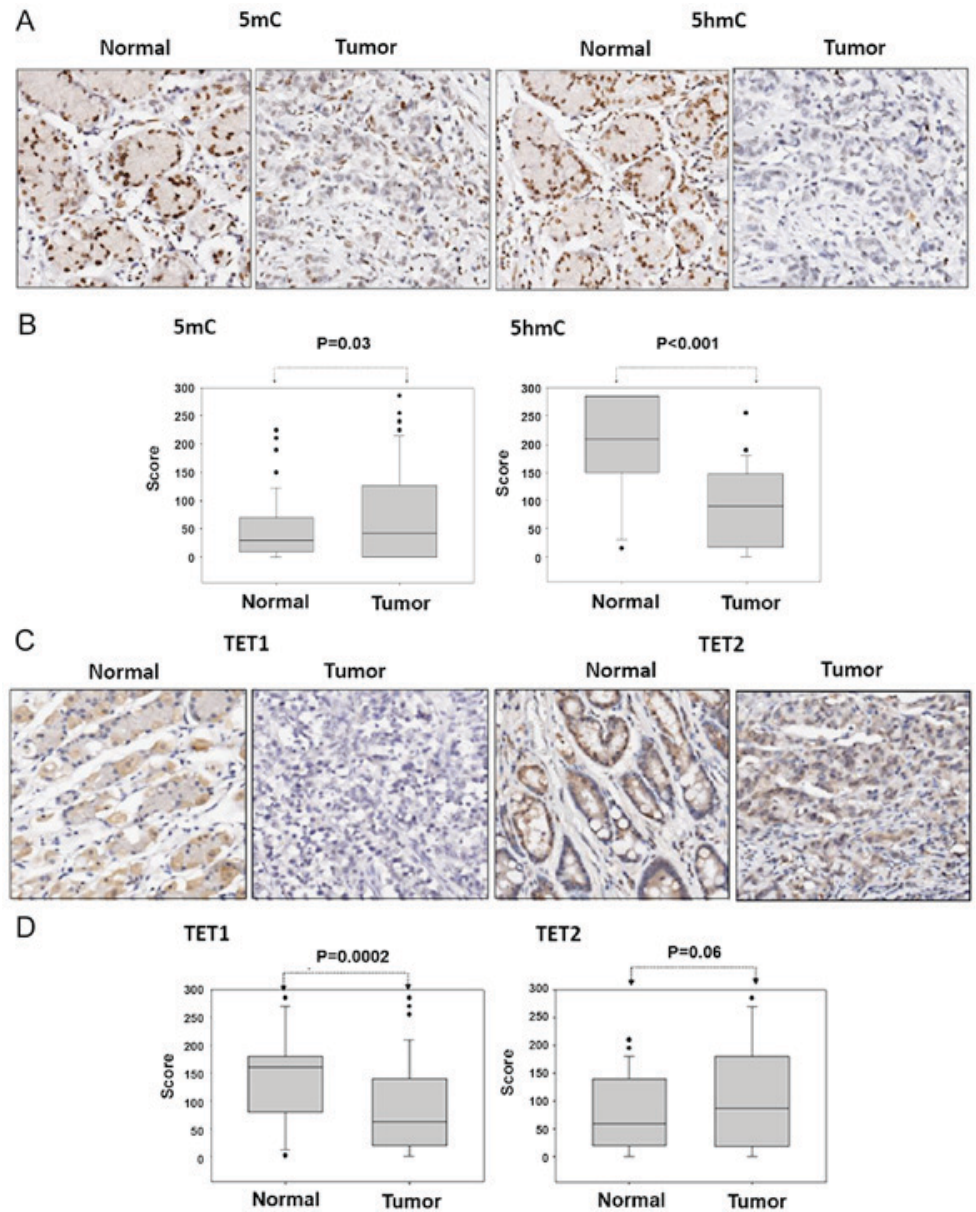

Figure 1. Expression levels of $5 \mathrm{mC}, 5 \mathrm{hmC}$, TET1 and TET2 were analyzed using IHC in gastric cancer tissue arrays. A representative case is presented in this figure. (A) The IHC assay analyzed the $5 \mathrm{mC}$ and $5 \mathrm{hmC}$ expression levels in a patient with gastric cancer (magnification, $\mathrm{x} 100$ ), and (B) the relative $5 \mathrm{mC}$ and $5 \mathrm{hmC}$ expression levels were scored between gastric cancer and adjacent normal tissues from 58 patients. (C) The IHC assay revealed the expression levels of TET1 and TET2 in a patient with gastric cancer (magnification, x100). (D) The relative expression levels of TET1 and TET2 were scored between the gastric cancer tissues of 58 patients and their corresponding adjacent normal tissues. IHC, immunohistochemistry; TET, ten-eleven translocation; 5mC, 5-methylcytosine; 5hmC, 5-hydroxymethylcytosine.

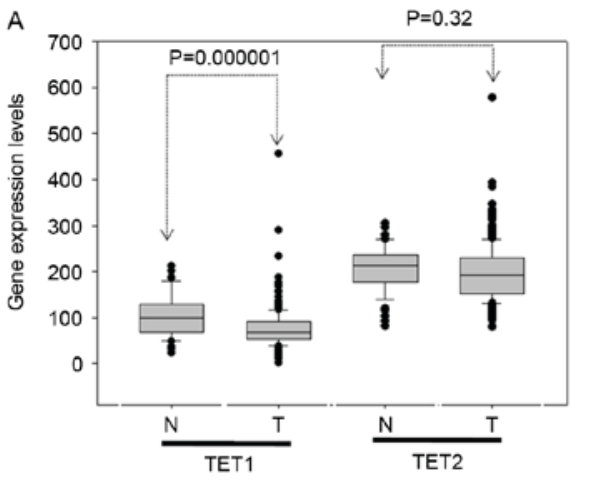

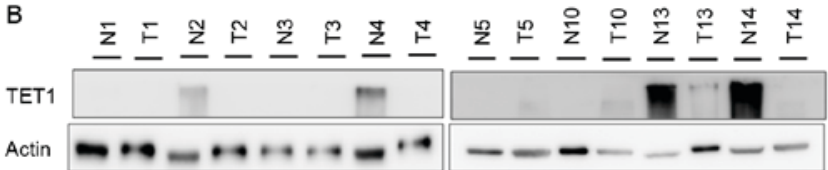

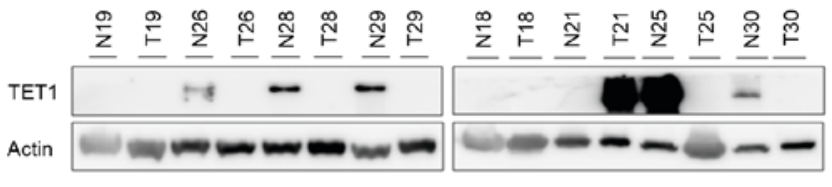

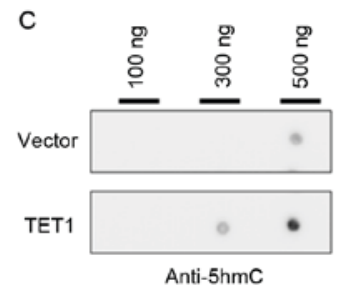

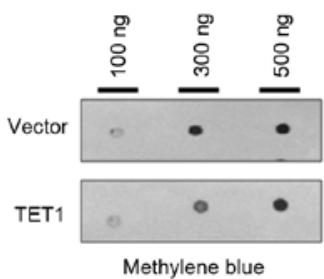

Figure 2. Expression levels of TET1 and TET2 in gastric cancer. (A) Expression levels of TET1 and TET2 were analyzed in 311 gastric cancer and 57 adjacent normal tissues from the Gene Expression Across Normal and Tumor Tissue database. (B) Expression levels of TET1 protein were decreased in gastric cancer tissues obtained from 16 patients with gastric cancer compared with the normal adjacent tissues. (C) TET1 overexpression increased the global 5 hmC expression levels in the genomic DNA of AGS cells. The loading control was visualized using methylene blue staining. N, normal; T, tumor; TET, ten-eleven translocation; 5mC, 5-methylcytosine; 5hmC, 5-hydroxymethylcytosine. 


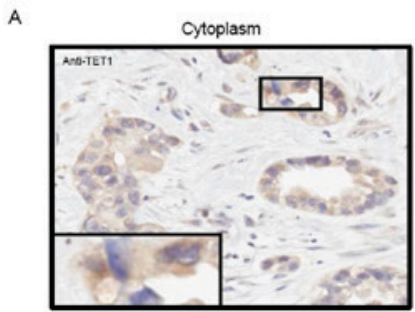

c

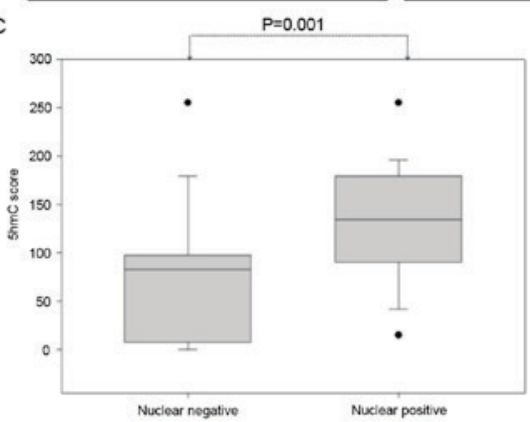

Cytoplasm + nuclear

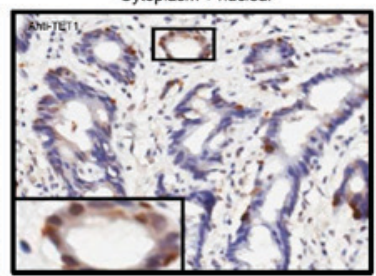

D
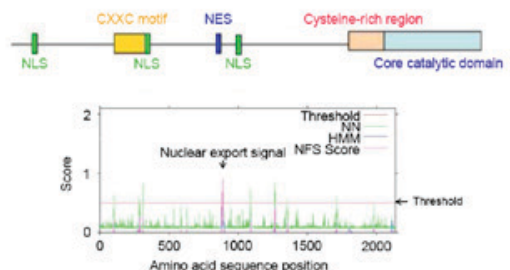

Nuclear

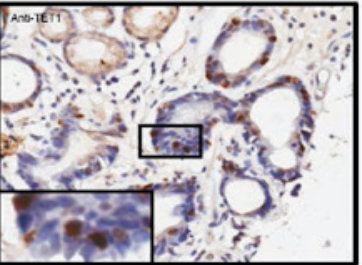

B
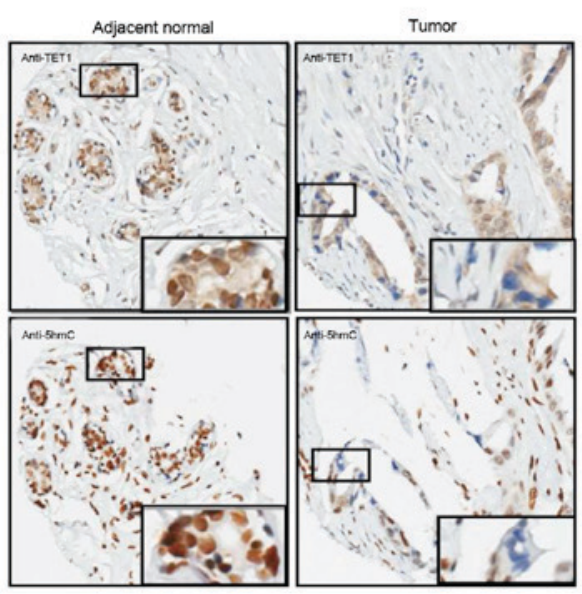

Figure 3. Various localizations of TET1 protein are associated with 5hmC status in human gastric cancer. (A) TET1 protein was exclusively expressed in the cytoplasm (left panel), in the cytoplasm and nucleus (middle panel) and predominantly in the nucleus (right panel) (magnification, x100). (B) The results of immunohistochemistry revealed that nuclear exclusion of TET1 protein was associated with $5 \mathrm{hmC}$ depletion in gastric cancer tissues (magnification, x100). (C) Nucleic TET1 protein expression was significantly associated with high $5 \mathrm{hmC}$ expression level in gastric cancer. (D) A schematic display of the structure of TET1 gene. An NES signal was identified in TET1 (aa877-889) using the ENS prediction tool (http://www.cbs.dtu.dk/services/NetNES/). TET, ten-eleven translocation; 5hmC, 5-hydroxymethylcytosine; NES, nuclear export signal; NLS, nuclear localization signals; NN, Neural Network; HMM, Hidden Markov Model.

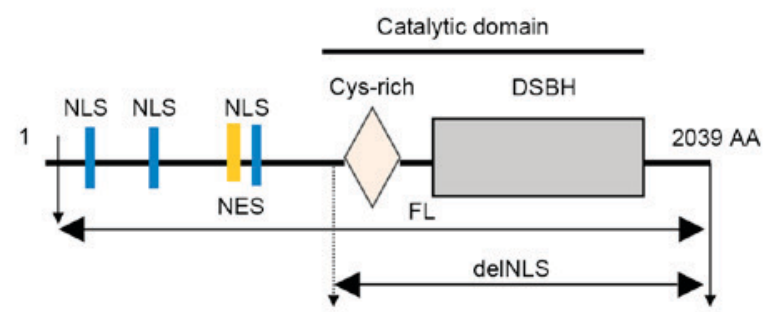

C

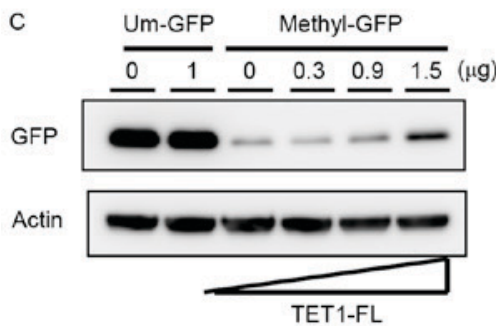

Unmethyl-GFP Methyl-GFP

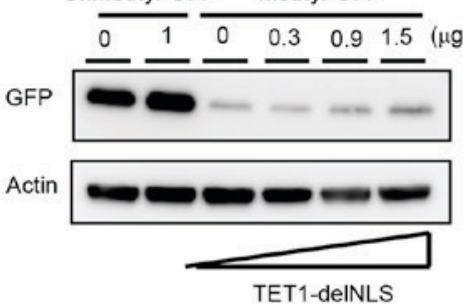

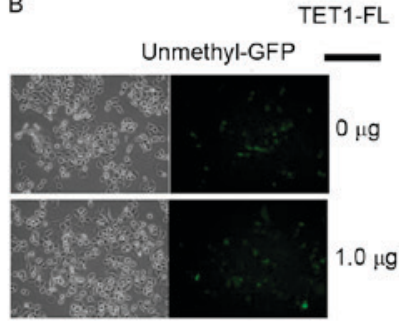

D

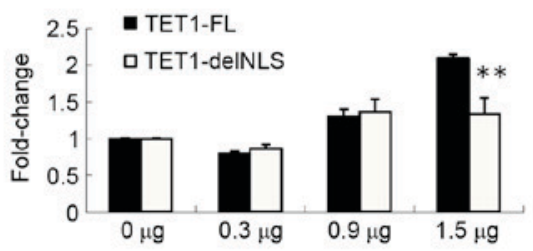

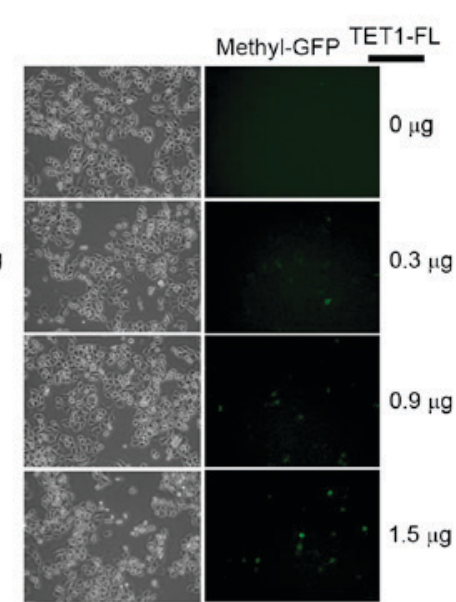

Figure 4. TET1 is involved in active DNA demethylation pathway in AGS cells. (A) Schematic diagrams of TET1 expression constructs for TET1-full length and TET1-delNLS. AGS cells were co-transfected with methylated GFP or unmethylated GFP, and TET1-FL or TET1-delNLS. Following transfection for $24 \mathrm{~h}$, the GFP expression was detected by (B) fluorescence microscopy (magnification, x 100) and (C) western blotting. (D) The intensity of GFP was quantified using Image J software and was represented graphically. ${ }^{* *} \mathrm{P}<0.01$. Actin was used as an internal control. TET, ten-eleven translocation; GFP, green fluorescent protein; NES, nuclear export signal; NLS, nuclear localization signals; TET1-FL, full length of TET1 genes; TET1-delNLS, NLS domain of TET1 was deleted.

NLS1:aa20-50, NLS2:aa620-653 and NLS3:1158-1162) and one nuclear export signal (NES; aa877-889) in the N-terminal region of TET1 protein (Fig. 3D). However, this result requires further confirmation by future studies. 
TET-1 localization may contribute to the active DNA demethylation signaling pathway. TET1 nuclear exclusion was associated with $5 \mathrm{hmC}$ depletion in gastric cancer tissues according to the IHC data, so the present study evaluated whether different cellular localizations of TET1 protein affected its demethylation activity by constructing two TET1 expression vectors, TET1-FL and TET1-delNLS. TET1 contains a critical catalytic domain and three NLSs, whereas TET1-delNLS contained only a catalytic domain (Fig. 4A). A reporter assay was used to assess DNA demethylation activity. The GFP plasmid was methylated in vitro with $\mathrm{CpG}$ methyltransferase (M.SssI). Furthermore, the completely methylated pEGFP plasmids were co-transfected into AGS cells with TET1-FL or TET1-delNLS. As presented in Fig. 4B, GFP expression was completely silenced in AGS cells transfected with the methylated GFP expression vector. Following co-transfection with the TET1-FL expression vector for $24 \mathrm{~h}$, the number of GFP-positive cells markedly increased (Fig. 4B). By performing western blot analysis, the present study observed that the GFP expression level increased 2.2-fold following transfection with $1.5 \mu \mathrm{g}$ TET1 (Fig. 4C and D). Compared with cells transfected with TET1-delNLS, the GFP expression level was slightly increased in cells transfected with $1.5 \mu \mathrm{g}$ of TET1-delNLS ( 1.3-fold). These results indicated that the nuclear localization of TET1 may serve a crucial role in the modulation of gene expression, particularly in gastric cancer.

\section{Discussion}

Previous studies have reported that $5 \mathrm{hmC}$ expression levels are significantly lower in gastric cancer tissues compared with in adjacent normal tissues (32-34). In addition, Yang et al (33) reported that a low $5 \mathrm{hmC}$ expression level is an independent factor for poor prognosis in patients with gastric cancer. They also reported that a low $5 \mathrm{hmC}$ expression level was associated with the majority of recorded clinicopathological characteristics, including the tumor size, stage, lymph node metastasis and overall survival rate. These results indicated that the mechanism underlying $5 \mathrm{hmC}$ depletion served a crucial role in gastric cancer progression. The results of the present study revealed that the potential mechanism underlying $5 \mathrm{hmC}$ expression level depletion in gastric cancer cells may be a low TET1 protein expression level. Furthermore, Yang et al (33) reported a strong association between the decrease in $5 \mathrm{hmC}$ expression levels and decrease in TET1 mRNA expression levels; however, this link was not observed for TET2 and TET3 proteins. Frycz et al (35) demonstrated that TET1 transcript and protein expression levels were associated with the metastasis stage in patients with gastric cancer. The results of the present study revealed that TET1 transcript and protein expression levels were significantly decreased in gastric cancer tissues compared with adjacent normal tissues. In addition, the present study observed a marked difference in subcellular localization. The localization of TET1 protein expression level in the nucleus was associated with $5 \mathrm{hmC}$ expression levels and contributed to the active demethylation process. Our previous study reported a similar phenomenon and revealed that the cytoplasmic mislocalization of TET1 reduced the expression level of $5 \mathrm{hmC}$ in breast cancer (25). A low $5 \mathrm{hmC}$ expression level is an effective independent prognostic biomarker for breast ductal carcinoma, particularly in patients with an endocrine receptor/progesterone receptor-negative subtype (25). Similarly, Müller et al (36) reported that a decrease in $5 \mathrm{hmC}$ expression levels is attributable to the nuclear exclusion of TET1 from the nuclei of glioma cells. Using the bioinformatics approach, the present study identified three NLSs and one NES in the N-terminal region of TET1 protein (Fig. 3D). This result suggested that TET1 protein shuttles between the nucleus and the cytoplasm. In conclusion, these results revealed that the nuclear-to-cytoplasm shuttling of TET proteins in tumor cells may be a critical event contributing to human cancer progression.

\section{Acknowledgements}

The present study was supported by the Kaohsiung Veterans General Hospital (grant no. VGHKS-105-016), the Zuoying Branch of Kaohsiung Armed Forces General Hospital (grant no. ZBH-103-27) and Yen Tjing Ling Medical Foundation (grant nos. CI-102-13 and CI-103-18).

\section{References}

1. Esteller M: Cancer epigenetics for the 21st Century: What's next? Genes Cancer 2: 604-606, 2011.

2. Dahl C, Grønbæk K and Guldberg P: Advances in DNA methylation: 5-hydroxymethylcytosine revisited. Clin Chim Acta 412: 831-836, 2011.

3. Sun M, Song CX, Huang H, Frankenberger CA, Sankarasharma D, Gomes S, Chen P, Chen J, Chada KK, He C and Rosner MR: HMGA2/TET1/HOXA9 signaling pathway regulates breast cancer growth and metastasis. Proc Natl Acad Sci USA 110: 9920-9925, 2013.

4. Lim B, Kim JH, Kim M and Kim SY: Genomic and epigenomic heterogeneity in molecular subtypes of gastric cancer. World $\mathrm{J}$ Gastroenterol 22: 1190-1201, 2016.

5. Yamamoto $\mathrm{H}$ and Imai K: Microsatellite instability: An update. Arch Toxicol 89: 899-921, 2015.

6. Kim KJ, Lee TH, Cho NY, Yang HK, Kim WH and Kang GH: Differential clinicopathologic features in microsatellite-unstable gastric cancers with and without MLH1 methylation. Hum Pathol 44: 1055-1064, 2013.

7. Ling ZQ, Tanaka A, Li P, Nakayama T, Fujiyama Y, Hattori T and Sugihara H: Microsatellite instability with promoter methylation and silencing of hMLH1 can regionally occur during progression of gastric carcinoma. Cancer Lett 297: 244-251, 2010.

8. Tsai KW, Hu LY, Wu CW, Li SC, Lai CH, Kao HW, Fang WL and Lin WC: Epigenetic regulation of miR-196b expression in gastric cancer. Genes Chromosomes Cancer 49: 969-980, 2010.

9. Tsai KW, Liao YL, Wu CW, Hu LY, Li SC, Chan WC, Ho MR, Lai CH, Kao HW, Fang WL, et al: Aberrant hypermethylation of miR-9 genes in gastric cancer. Epigenetics 6: 1189-1197, 2011.

10. Tsai KW, Wu CW, Hu LY, Li SC, Liao YL, Lai CH, Kao HW, Fang WL, Huang KH, Chan WC and Lin WC: Epigenetic regulation of miR-34b and miR-129 expression in gastric cancer. Int $\mathrm{J}$ Cancer 129: 2600-2610, 2011.

11. Qu Y, Dang S and Hou P: Gene methylation in gastric cancer. Clin Chim Acta 424: 53-65, 2013.

12. Ehrlich M, Gama-Sosa MA, Huang LH, Midgett RM, Kuo KC, McCune RA and Gehrke C: Amount and distribution of 5-methylcytosine in human DNA from different types of tissues of cells. Nucleic Acids Res 10: 2709-2721, 1982.

13. Jin SG, Wu X, Li AX and Pfeifer GP: Genomic mapping of 5 -hydroxymethylcytosine in the human brain. Nucleic Acids Res 39: 5015-5024, 2011.

14. Koh KP, Yabuuchi A, Rao S, Huang Y, Cunniff K, Nardone J, Laiho A, Tahiliani M, Sommer CA, Mostoslavsky G, et al: Tet1 and Tet2 regulate 5-hydroxymethylcytosine production and cell lineage specification in mouse embryonic stem cells. Cell Stem Cell 8: 200-213, 2011.

15. Pastor WA, Pape UJ, Huang Y, Henderson HR, Lister R, Ko M, McLoughlin EM, Brudno Y, Mahapatra S, Kapranov P, et al: Genome-wide mapping of 5-hydroxymethylcytosine in embryonic stem cells. Nature 473: 394-397, 2011. 
16. Cimmino L, Abdel-Wahab O, Levine RL and Aifantis I: TET family proteins and their role in stem cell differentiation and transformation. Cell Stem Cell 9: 193-204, 2011.

17. Ficz G, Branco MR, Seisenberger S, Santos F, Krueger F, Hore TA, Marques CJ, Andrews S and Reik W: Dynamic regulation of 5-hydroxymethylcytosine in mouse ES cells and during differentiation. Nature 473: 398-402, 2011.

18. Gu TP, Guo F, Yang H, Wu HP, Xu GF, Liu W, Xie ZG, Shi L, He X, Jin SG, et al: The role of Tet3 DNA dioxygenase in epigenetic reprogramming by oocytes. Nature 477: 606-610, 2011.

19. Guo JU, Su Y, Zhong C, Ming GL and Song H: Emerging roles of TET proteins and 5-hydroxymethylcytosines in active DNA demethylation and beyond. Cell Cycle 10: 2662-2668, 2011.

20. He YF, Li BZ, Li Z, Liu P, Wang Y, Tang Q, Ding J, Jia Y, Chen Z, Li L, et al: Tet-mediated formation of 5-carboxylcytosine and its excision by TDG in mammalian DNA. Science 333: 1303-1307, 2011.

21. Ito S, D'Alessio AC, Taranova OV, Hong K, Sowers LC and Zhang Y: Role of Tet proteins in $5 \mathrm{mC}$ to $5 \mathrm{hmC}$ conversion, ES-cell self-renewal and inner cell mass specification. Nature 466: 1129-1133, 2010.

22. Ito S, Shen L, Dai Q, Wu SC, Collins LB, Swenberg JA, He C and Zhang Y: Tet proteins can convert 5-methylcytosine to 5-formylcytosine and 5-carboxylcytosine. Science 333: 1300-1303, 2011.

23. Hsu CH, Peng KL, Kang ML, Chen YR, Yang YC, Tsai CH, Chu CS, Jeng YM, Chen YT, Lin FM, et al: TET1 suppresses cancer invasion by activating the tissue inhibitors of metalloproteinases. Cell Rep 2: 568-579, 2012.

24. Williams K, Christensen J, Pedersen MT, Johansen JV, Cloos PA, Rappsilber J and Helin K: TET1 and hydroxymethylcytosine in transcription and DNA methylation fidelity. Nature 473: 343-348, 2011.

25. Tsai KW, Li GC, Chen CH, Yeh MH, Huang JS, Tseng HH, Fu TY, Liou HH, Pan HW, Huang SF, et al: Reduction of global 5-hydroxymethylcytosine is a poor prognostic factor in breast cancer patients, especially for an ER/PR-negative subtype. Breast Cancer Res Treat 153: 219-234, 2015.

26. Kinney SR and Pradhan S: Ten eleven translocation enzymes and 5-hydroxymethylation in mammalian development and cancer. Adv Exp Med Biol 754: 57-79, 2013.

27. Pérez C, Martínez-Calle N, Martín-Subero JI, Segura V, Delabesse E, Fernandez-Mercado M, Garate L, Alvarez S, Rifon J, Varea S, et al: TET2 mutations are associated with specific 5-methylcytosine and 5-hydroxymethylcytosine profiles in patients with chronic myelomonocytic leukemia. PLoS One 7: e31605, 2012.
28. Yang H, Liu Y, Bai F, Zhang JY, Ma SH, Liu J, Xu ZD, Zhu HG, Ling ZQ, Ye D, et al: Tumor development is associated with decrease of TET gene expression and 5-methylcytosine hydroxylation. Oncogene 32: 663-669, 2013.

29. Shin G, Kang TW, Yang S, Baek SJ, Jeong YS and Kim SY: GENT: Gene expression database of normal and tumor tissues. Cancer Inform 10: 149-157, 2011.

30. Duhamel RC, Meezan E and Brendel K: The addition of SDS to the Bradford dye-binding protein assay, a modification with increased sensitivity to collagen. J Biochem Biophys Methods 5: 67-74, 1981.

31. la Cour T, Kiemer L, Mølgaard A, Gupta R, Skriver K and Brunak S: Analysis and prediction of leucine-rich nuclear export signals. Protein Eng Des Sel 17: 527-536, 2004.

32. Park JL, Kim HJ, Seo EH, Kwon OH, Lim B, Kim M, Kim SY, Song KS, Kang GH, Kim HJ, et al: Decrease of $5 \mathrm{hmC}$ in gastric cancers is associated with TET1 silencing due to with DNA methylation and bivalent histone marks at TET1 CpG island 3'-shore. Oncotarget 6: 37647-37662, 2015.

33. Yang Q, Wu K, Ji M, Jin W, He N, Shi B and Hou P: Decreased 5-hydroxymethylcytosine $(5-\mathrm{hmC})$ is an independent poor prognostic factor in gastric cancer patients. J Biomed Nanotechnol 9: 1607-1616, 2013.

34. Kudo Y, Tateishi K, Yamamoto K, Yamamoto S, Asaoka Y, Ijichi H, Nagae G, Yoshida H, Aburatani H and Koike K: Loss of 5-hydroxymethylcytosine is accompanied with malignant cellular transformation. Cancer Sci 103: 670-676, 2012.

35. Frycz BA, Murawa D, Borejsza-Wysocki M, Marciniak R, Murawa P, Drews M, Kołodziejczak A, Tomela K and Jagodziński PP: Decreased expression of ten-eleven translocation 1 protein is associated with some clinicopathological features in gastric cancer. Biomed Pharmacother 68: 209-212, 2014.

36. Müller T, Gessi M, Waha A, Isselstein LJ, Luxen D, Freihoff D, Freihoff J, Becker A, Simon M, Hammes J, et al: Nuclear exclusion of TET1 is associated with loss of 5-hydroxymethylcytosine in IDH1 wild-type gliomas. Am J Pathol 181: 675-683, 2012.

This work is licensed under a Creative Commons Attribution-NonCommercial-NoDerivatives 4.0 International (CC BY-NC-ND 4.0) License. 